\title{
PRINSIP PENDIDIKAN AGAMA ISLAM DALAM MEWUJUDKAN KESEHATAN MENTAL DAN GOOD GOVERNMENT
}

\author{
Muhamad Fatihul Afham \\ UIN Syarif Hidayatullah Jakarta \\ fatehalafham@gmail.com \\ Moh. Salapudin \\ UIN Walisongo Semarang \\ catatankangsalap@gmail.com
}

\begin{abstract}
This study aims to determine the principles of Islamic religious education in realizing mental health, as well as the role of Islamic education in creating good government. This study uses a qualitative approach with library research methods (literature study). Collecting data using documentation techniques. The data analysis used descriptive analysis techniques.

The results showed that religion is an important element in mental development. Without religion, development plans will not be carried out properly. Because a person can carry out his plans properly depending on the calm of his soul. If his soul is restless he will not be able to deal with the problems inherent in implementing these plans. A mentality that grows without religion will not necessarily be able to achieve integrity due to a lack of peace and tranquility of the soul.

Islamic Religious Education is education based on the teachings of the Islamic religion, namely in the form of guidance, care for students, so that later after completing education, they can understand, live and practice the teachings of Islam as a way of life for the sake of safety and welfare of life in this world and in the hereafter. Thus, if Islamic religious education can become a way of life for each individual, then mental health and goo govermunt will automatically be realized.
\end{abstract}

Kata Kunci: Pendidikan Agama Islam, Kesehatan Mental, Good Government

\section{A. Pendahuluan}

Kesehatan mental merupakan permasalahan yang aktual dan relevan dengan realitas dan kebutuhan masyarakat. ${ }^{1}$ Kesehatan mental menurut Undang-Undang Nomor 18 Tahun 2014, Bab 1 Pasal 1 adalah "kondisi di mana seorang individu dapat berkembang secara fisik, mental, spiritual dan sosial sehingga individu tersebut menyadari kemampuan sendiri dapat mengatasi tekanan dapat bekerja secara produktif dan mampu memberikan kontribusi untuk komunitasnya."2

Kesehatan mental merupakan permasalahan yang selalu menarik perhatian bagi siapapun. Mahasiswa depresi karena belum menyelesaikan kuliah, siswa yang putus sekolah karena tidak ada biaya, remaja mengkonsumsi narkoba, tawuran antarpelajar

\footnotetext{
${ }^{1}$ Widayatun, \& Fatoni, Z. Kesehatan Mental dalam Kedaruratan, Jurnal Kependudukan Indonesia, $2013,7$.

${ }^{2}$ Undang-Undang Republik Indonesia Nomor 18 Tahun 2014 Tentang Kesehatan Jiwa
} 
sampai meninggal, anak-anak yang terlibat pornografi maupun pornoaksi, seorang ayah tega membunuh anaknya karena masalah ekonomi, kekerasan dalam rumah tangga, pejabat pemerintahan tidak bersih hal tersebut merupakan permasalahan yang tidak bisa diabaikan begitu saja. ${ }^{3}$

Kondisi mental memang sangat menentukan dalam hidup ini. Hanya orang yang sehat mentalnya sajalah yang dapat merasa bahagia dan sanggup menghadapi kesulitankesulitan atau rintangan hidup. Apabila kesehatan mental terganggu akan muncul gejala-gejalanya dalam segala aspek kehidupan, misalnya perasaan, kelakuan, pikiran dan kesehatan. Dalam pemerintahan khususnya pemimpin dituntut unktuk "Berpikir masif" meliputi aktivitas mental. Misalnya berpikir saat memutuskan mengerjakan pekerjaan tertentu, berpikir tentang membeli barang tertentu, berpikir tentang karyawan mana yang perlu dipromosikan dan sebagainya. Para ahli mendefinisikan tentang berpikir, antara lain: Suatu kegiatan mental yang melibatkan kerja otak dan melibatkan seluruh pribadi manusia dan juga melibatkan perasaan kehendak. ${ }^{4}$

Contoh dalam kehidupan remaja beberapa tahun yang lalu, tepatnya pada hari Senin tanggal 29 Mei 2017 di Pamulang, Tangerang Selatan, Banten. Warga RT 01/02 Kelurahan Pondok Cabe, Pamulang, Tangerang Selatan digegerkan dengan penemuan mayat bayi.

"Pelaku SP dan RK melakukan Aborsi terhadap janin tersebut karena mereka berdua bukanlah pasangan suami-istri. SP statusnya masih bersuami dan sedang pisah ranjang dengan suaminya. Dari hubungan tersebut SP hamil," kata Kapolres Tangsel, AKBP Fadli Widiyanto di Polres Tangsel. Fadli menambahkan, setelah mengetahui SP hamil, RK yang takut ketahuan meminta kekahsihnya itu untuk menggugurkan janin. Selain itu, RK juga masih punya hubungan kekerabatan dengan suami sah SP."5

Contoh kejadian di atas adalah termasuk dari gejala mental yang tidak sehat. Karena tindakan yang diperbuatnya tersebut sangatlah mengancam dirinya sendiri. Hal tersebut mengakibatkan ketidakselamatan dan ketidakbahagiaan di dunia dan di akhirat(Wijayanti, 2016: 315). Perbuatan tersebut menimbulkan perasaan takut dan cemas. Sudah seharusnya manusia senantiasa ingat kepada Tuhannya supaya diberi ketenangan dalam hatinya agar dapat bertindak dan berperilaku sesuai ajaran agama. Sesuai dengan Q.S Al-Fath ayat 4:

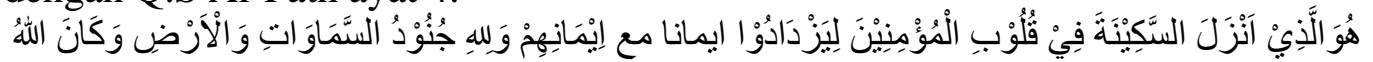

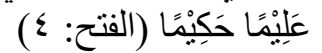

"Dialah yang telah menurunkan ketenangan ke dalam hati orang-orang mukmin untuk menambah keimanan atas keimanan mereka (yang telah ada). Dan milik Allah-lah tentara langit dan bumi dan adalah Allah Maha Mengetahui lagi Maha Bijaksana." (Q.S. Al-Fath [48]: 4) ${ }^{6}$

Masalah kesehatan mental tidak hanya menjadi tumpuan perhatian bidang psikologi saja, tetapi juga oleh berbagai bidang di antaranya adalah pendidikan. Kesehatan mental merupakan ilmu pengetahuan yang praktis, sebagai pengejawantahan ilmu jiwa di dalam pergaulan hidup. Pandangan terhadap ilmu kesehatan mental ini agak berbeda-beda sesuai dengan lapangan hidup, keahlian dan kepentingan masing-

\footnotetext{
${ }^{3}$ Hasanah, M. Pengaruh Gadget terhadap Kesehatan Mental Anak. Indonesian Journal of Islamic Early Childhood Education. 2017, 212.

${ }^{4}$ Hernawaty, T., Setyorini, D., Maulana, I., \& Arifin, H. S. Pembentukan Kader Kesehatan Jiwa Di Kabupaten Pangandaran. Jurnal Pengabdian Kepada Masyarakat. 2018, 818.

${ }^{5}$ Detiknews.com Senin, 29 Mei 2017 diakses pada Selasa, 6 November 2017 Pukul 10.30 WIB.

${ }^{6}$ (Kementrian Agama RI, Al-Qur'an dan Terjemahannya, (Jakarta: PT. Tehazed, 2010), 737.)
} 
masing. Sedangkan para pendidik lebih menitikberatkan pandangannya terhadap bahaya-bahaya yang melanggar norma-norma sosial, tata tertib, norma susila dan lain sebagainya.

Bangsa Indonesia masih terus dihadapkan pada krisis multidimensional. Dari hasil berbagai kajian disiplin dan pendekatan ada kesamaan pandangan bahwa segala macam krisis tersebut berpangkal pada krisisnya akhlak dan moral. Dengan kata lain, krisis akhlak dan moral ini disebabkan oleh gagalnya pendidikan. Kontribusi pendidikan dalam konteks ini adalah pada pembangunan mentalitas manusianya yang merupakan hasil dari proses pendidikan. Sementara pihak lain menyebutkan bahwa adanya krisis tersebut karena kegagalan pendidikan agama, termasuk di dalamnya Pendidikan Agama Islam. ${ }^{7}$ Menurut Abdul Majid untuk mengantisipasi berbagai krisis tersebut, maka pembelajaran agama Islam di sekolah maupun di Perguruan Tinggi harus menunjukkan kontribusinya. ${ }^{8}$

\section{B. Kesehatan Mental}

Istilah kesehatan mental dikalangan masyarakat pada umumnya sangatlah kurang terkenal sehingga sering terjadi salah kaprah pemahaman masyarakat tentang kesehatan mental. Sebelum sampai pada suatu pengertian tertentu, terlebih dahulu perlu adanya kejelasan tentang apa yang dimaksud dengan kesehatan dan mental dalam pembahasan ini. Sebab, sering terdengar di masyarakat mental itu digunakan pada pengertian lain. Seperti contoh dalam masalah kesukuan, kita mengenal istilah mental orang Jawa, mental orang Minang, mental orang Bugis atau istilah mental juara, mental tempe dan lain-lain. Sedangkan sehat adalah konsep yang tidak mudah diartikan meskipun sehat itu dapat dirasakan dan diamati. Misalnya orang yang tidak punya keluhan sakit fisik dia dianggap sehat. Atau orang yang gemuk, dianggap oleh sebagian orang juga sehat. Faktor subjektivitas dan kultur memengaruhi pengertian dan pemahaman terhadap konsep sehat. ${ }^{9}$

Sehat secara bahasa adalah keadaan yang baik seluruh anggota badan serta bagian-bagianya. ${ }^{10}$ Secara istilah World Health Organization (WHO) menyebutkan sehat adalah "a state of complete physical, mental and social well-being and not marely the absence of disease or infirmity." "11

Moeljono Notosoedirdjo menambahkan, sehat mengandung pengertian keadaan yang sempurna secara biopsikososial, lebih dari sekadar terbebas dari penyakit atau kecacatan. ${ }^{12}$

Sedangkan Kesehatan menurut Undang-Undang Republik Indonesia Nomor 36 Tahun 2009 adalah keadaan sehat, baik secara fisik, mental, spiritual, maupun sosial, yang memungkinkan setiap orang untuk hidup produktif secara sosial dan ekonomis. ${ }^{13}$

7 Idi, A., \& Sahrodi, J. Moralitas Sosial dan Peranan Pendidikan Agama. Intizar. 2017, 9. https://doi.org/10.19109/intizar.v23i1.1316

8 Abdul Majid, Belajar dan Pembelajaran Pendidikan Agama Islam, (Bandung: Remaja Rosdakarya offset, 2014), Cet. II, 9.

${ }^{9}$ Ryadi, A. L. S. Ilmu kesehatan masyarakat. Penerbit Andi. 2016, 335.

${ }^{10}$ Kemendikbud RI, 2016

${ }^{11}$ World Health Organization, Promoting Mental Health: Concepts, Emerging Evidence, Practice: A Report of the World Health Organization, (Departement of Mental Health and Substance Abuse in collaboration with the Victorian Health Promotion Foundation and the University of Melbourne, 2004), 120.

${ }^{12}$ Moeljono Notosoedirdjo dan Latipun, Kesehatan Mental: Konsep dan Penerapan, (Malang: UMM Press, 2014), Cet. I, Edisi Keempat, 11. 
Mental secara bahasa adalah batin, watak, atau hal yang menyangkut batin dan watak manusia yang bukan bersifat badan atau tenaga. Sedangkan secara istilah, mental adalah unsur jiwa termasuk pikiran, emosi, sikap dan perasaan yang dalam keseluruhan dan kebulatannya akan menentukan corak tingkah laku, cara menghadapi suatu hal yang menentukan perasaan, mengecewakan dan menyenangkan. ${ }^{14}$

Istilah kesehatan mental diambil dari konsep mental hygiene. Kata mental diambil dari bahasa Latin mens, mentis yang artinya jiwa, nyawa, sukma, roh, semangat. ${ }^{15}$ Kata tersebut mempunyai pengertian yang sama dengan psyche dalam bahasa Yunani yang artinya psikis, jiwa, atau kejiwaan. ${ }^{16}$ Sedangkan kata "hygiene" berasal dari kata hygea yaitu nama seorang dewa perempuan yang bertugas mengurus masalah kesehatan manusia di dunia dalam kepercayaan Yunani Kuno. Dari kata "hygea" itu kemudian muncul kata "hygiene" yang artinya kegiatan yang bertujuan mencapai kesehatan. ${ }^{17}$

Kesehatan mental atau mental health menurut WHO adalah " $a$ state of well-being in which the individual realizes his or her own abilities, can cope with the normal stresses of life, can work productively and fruitfully, and is able to make contribution to his or her community." 18

Sedangkan menurut Undang-Undang Nomor 18 Tahun 2014, Bab 1 Pasal 1 kesehatan mental adalah "kondisi di mana seorang individu dapat berkembang secara fisik, mental, spiritual, dan sosial sehingga individu tersebut menyadari kemampuan sendiri, dapat mengatasi tekanan, dapat bekerja secara produktif, dan mampu memberikan kontribusi untuk komunitasnya. ${ }^{19}$

Dengan melihat definisi sehat dan mental serta kesehatan mental secara bahasa dan istilah di atas sebagai disiplin ilmu, maka definisi tersebut sebagai tolak ukur untuk memahami arti kesehatan mental dengan benar.

Abdul Aziz El-Quussiy menjelaskan bahwa yang dimaksud kesehatan mental adalah "keserasian yang sempurna atau integrasi antara fungsi-fungsi jiwa yang bermacam-macam, disertai kemampuan untuk menghadapi goncangan-goncangan jiwa yang ringan, yang bisa terjadi pada orang, di samping secara positif dapat merasakan kebahagian dari kemampuan."20

Dalam Dimensi Religi dalam Praktek Psikiatri dan Psikologi karya Dadang Hawari telah menyempurnakan batasan sehat dengan menambahkan dimensi agama sehingga sekarang ini yang dimaksud dengan sehat adalah tidak hanya sehat secara fisik, psikologis dan sosial, akan tetapi juga sehat dalam arti spiritual. Empat dimensi itu antara lain: Spiritual-Agama, Organo-Biologik, Psiko-Edukatif dan Sosial-Budaya. ${ }^{21}$

\footnotetext{
13 .(Undang-Undang Republik Indonesia Nomor 36 Tahun 2009 Tentang Kesehatan)

${ }^{14} \mathrm{KBBI}$

15 Kartini Kartono dan Jenny Andari, Hygiene Mental dan Kesehatan Mental dalam Islam, (Bandung: Mandar Maju, 1989), Cet. VI, 3.

${ }_{17}^{16}$ Moeljono Notosoedirdjo dan Latipun, Kesehatan Mental..., 23.

${ }^{17}$ Syamsu Yusuf, Kesehatan Mental Persepektif Psikologis dan Agama, (Bandung: PT Remaja Rosdakarya, 2018), Cet. I, 9.

${ }^{18}$ World Health Organization, Promoting Mental Health....

${ }^{19}$ Undang-Undang Republik Indonesia Nomor 18 Tahun 2014 Tentang Kesehatan Jiwa

20 Abdul Aziz El Quussiy, Pokok-Pokok Kesehatan Mental, Terj. dari Ususus Shihhah AnNafsiyyah oleh Zakiah Daradjat, (Jakarta: Bulan Bintang, 1986), Cet. II, 14.

${ }^{21}$ Dadang Hawari, Dimensi Religi dalam Praktek Psikiatri dan Psikologi, (Jakarta: FKUI, 2005), 5.
} 


\section{Tanda-Tanda Kesehatan Mental}

Lebih jelas lagi Syamsu Yusuf memaparkan tanda-tanda mental yang sehat dalam tabel berikut:

1.1. Tabel mental yang sehat menurut Syamsu Yusuf. ${ }^{22}$

\begin{tabular}{|c|c|}
\hline $\begin{array}{l}\text { ASPEK } \\
\text { PRIBADI }\end{array}$ & KARAKTERISTIK \\
\hline 1. Fisik & $\begin{array}{l}\text { Perkembangannya normal. } \\
\text { Berfungsi untuk melakukan tugas-tugasnya. } \\
\text { Sehat, tidak sakit-sakitan. }\end{array}$ \\
\hline Psikis & $\begin{array}{l}\text { a. } \quad \text { Respek terhadap diri sendiri dan orang lain. } \\
\text { b. } \quad \text { Memiliki insight dan rasa humor. } \\
\text { c. } \quad \text { Memiliki respon emosional yang wajar. } \\
\text { d. } \quad \text { Mampu berpikir realistis dan objektif. } \\
\text { e. } \quad \text { Terhindar dari gangguan-gangguan psikologis. } \\
\text { f. } \quad \text { Bersifat kreatif dan inovatif. } \\
\text { g. } \quad \text { Bersifat terbuka dan fleksibel, tidak defensif. } \\
\text { h. Memiliki perasaan bebas untuk memilih, } \\
\text { menyatakan pendapat dan bertindak. }\end{array}$ \\
\hline Sosial & $\begin{array}{l}\text { a. Memiliki rasa empati dan kasih sayang terhadap } \\
\text { orang lain, serta gampang memberi pertolongan kepada } \\
\text { yang membutuhkan. } \\
\text { b. Mampu berhubungan dengan orang lain secara } \\
\text { sehat, penuh cinta kasih dan persahabatan. } \\
\text { c. Bersifat toleran dan mau menerima orang lain } \\
\text { tanpa memandang kelas sosial, tingkat pendidikan, politik, } \\
\text { agama, suku, rasa tau warna kulit. }\end{array}$ \\
\hline Spiritual & $\begin{array}{l}\text { a. Beriman kepada Allah dan taat mengamalkan } \\
\text { ajaran-Nya. } \\
\text { b. Berakhlak mulia, seperti: jujur, amanah, tanggung } \\
\text { jawab, syukur, sabar, dan ikhlas dalam beramal. }\end{array}$ \\
\hline
\end{tabular}

Orang yang mentalnya sehat tentu hidupnya akan produktif dan kontributif. Maksud produktif di sini adalah kemampuan untuk membangun dirinya sendiri ke arah pencapaian sosok pribadi yang matang, mandiri dan dewasa dalam berpikir dan bersikap. Sedangkan kontributif adalah kemampuan memberikan nilai manfaat bagi orang lain dan lingkungan sekitarnya. Orang yang memiliki mental yang sehat akan bersikap secara tepat dan bisa diterima oleh masyarakat pada umumnya. Perilaku hidupnya sesuai dengan norma dan pola hidup kelompok masyarakat, sehingga ada relasi interpersonal dan intersosial yang baik antarindividu atau komunitas masyarakat. $^{23}$

\section{Faktor Mempengaruhi Kesehatan Mental}

\footnotetext{
${ }^{22}$ Syamsu Yusuf, Kesehatan Mental Persepektif..., 33.

${ }^{23}$ Rahmawati, H. (2018). Pengembangan Instrumen Intensi Perilaku Peduli Lingkungan pada Mahasiswa dan Faktor-Faktor Pembentuknya. Jurnal Sains Psikologi, 5 (1): 2.
} 
Secara sederhana dapat dijelaskan gangguan mental itu menghalangi seseorang untuk hidup sehat seperti yang diinginkan baik oleh individu itu sendiri maupun orang lain. Jumlah gangguan mental yang dapat diidentifikasi hampir tidak terbatas mulai dari kesulitan-kesulitan emosional yang singkat sampai pada gangguan kesehatan mental yang ringan dan berat. ${ }^{24}$

Orang yang sehat mentalnya senantiasa merasa aman dan bahagia dalam kondisi apapun. dia juga akan melakukan introspeksi diri atas segala hal yang dilakukannya sehingga ia mampu mengontrol dan mengendalikan dirinya sendiri.

Faktor yang memengaruhi kesehatan mental banyak sekali. Misalnya seperti kemiskinan, rendahnya tingkat pendidikan, pengahasilan rendah, pengalaman hidup, perasaan putus asa, tindak kekerasan, perubahan sosial yang sangat cepat adalah beberapa contoh yang dapat memengaruhi kesehatan mental seseorang. Ini sejalan dengan pendapat World Health Organization (WHO) yang menyatakan bahwa:

"Mental health and mental illnesses are determined by multiple and interacting social, psychological, and biological factors, just as health and illness in general. The clearest evidence for this relates to the risk of mental illness, which in the developed and developing world is associated with indicators of proverty, including low levels of education, and in some studies with poor housing and low income. The greater vulnerability of disadvantaged people in each community to mental illnesses may be explained by such factors as the experience of insecurity and hopelessness, rapid social change, and the risks of violence and physical ill-health. ${ }^{, 25}$

Dari berbagai sumber data yang ditemukan, faktor-faktor yang memengaruhi kesehatan mental dapat diklasifikasikan menjadi empat dimensi, yaitu faktor fisik biologis, psikologis, lingkungan dan sosial budaya.

a. Faktor fisik biologis

Menurut Moeljono Notosoedirdjo beberapa aspek fisik biologis yang secara langsung berpengaruh terhadap kesehatan mental di antaranya adalah otak, sistem endoktrin, genetik (keturunan), sensorik, dan kondisi ibu saat hamil. ${ }^{26}$

b. Faktor psikologis

menurut Syamsu Yusuf yaitu persepsi, perasaan dan emosi, situasi, pengalaman hidup, keputusan hidup, perilaku, reaksi perlawan, reaksi melarikan diri, dan imobilitas atau ketidakmampuan mengambil keputusan. ${ }^{27}$

c. Faktor sosial budaya

Abdullah Nashih Ulwan menjelaskan faktor sosial budaya yang memengaruhi kesehatan mental di antaranya: kemiskinan, perselisihan antara orang tua, perceraian, kekosongan waktu, pergaulan, perlakuan buruk orang tua, menonton film-film sadis dan porno, pengangguran, kelalaian orang tua, dan yatim atau piatu. ${ }^{28}$

d. Faktor lingkungan

Lingkungan fisik yang ada di sekitar dapat menyebabkan tekanan-tekanan psikologis dan sangat tidak baik bagi kondisi mental. Agresivitas, stres, tekanan mental, dan sebagainya menjadi meningkat jika kondisi lingkungan fisik di sekitar sudah di ambang

${ }^{24}$ Yustinus Semiun, Kesehatan Mental 1, (Kanisius: Yogyakarta, 2006), 9.

${ }^{25}$ World Health Organization, Promoting Mental Health..., 10.

${ }^{26}$ Moeljono Notosoedirdjo dan Latipun, Kesehatan Mental..., 62.

${ }^{27}$ Syamsu Yusuf, Kesehatan Mental Persepektif..., 131-139.

${ }^{28}$ Abdullah Nashih Ulwan, Tarbiyatul Aulad: Pendidikan Anak dalam Islam, Terj. dari Tarbiyatul Aulad Fil Islam, oleh Emiel Ahmad, (Jakarta: Khatulistiwa Press, 2017), Cet. V, 53-69. 
batas normal. Lingkungan fisik yang sangat memengaruhi antara lain tata ruang, penyinaran, udara, kebisingan dan polusi. ${ }^{29}$

Selain itu, cuaca, peristiwa alam seperti gempa bumi, tanah longsor, banjir dan lain-lain juga turut berpengaruh pada kesehatan mental. ${ }^{30}$

\section{E. Gangguan kesehatan mental}

Gangguan mental dalam beberapa hal disebut sebagai perilaku abnormal (abnormal behavior), yang juga dianggap sama dengan sakit mental (mental illness), sakit jiwa (insanity, lunacy, madness). Selain itu terdapat pula istilah-istilah serupa yaitu: distress, discontrol, disadvantage, disability, inflexibility, irrationally, syndromal pattern dan disturbance. Berbagai istilah ini dalam beberapa hal dianggap sama, namun terkadang digunakan secara berbeda. Dalam International Classification of Diseases (ICD) dan Diagnostic and Statistical Manual of Mental Disorders (DSM) digunakan istilah "mental disorder" yang diterjemahkan menjadi gangguan jiwa. ${ }^{31}$

Gangguan mental dalam Al-Qur'an dikatakan sebagai penyakit hati. Penyakit hati yang menyebabkan gangguan mental seseorang di antaranya hasud, iri, dengki, dusta, takabbur (sombong), khauf (takut), riya' (pamer), ananiyah (keakuan/egois), marah, tidak sabar dan sebagainya.

Sebagaimana dalam Q.S. Al-Baqarah ayat 10:

$$
\text { في قلوبهم مرض فز ادهم الله مرضا ولهم عذاب اليم بما كانو ا يكذ بون.(البقرة: ا ) ) }
$$

"Dalam hati mereka ada penyakit, lalu Allah menambah lagi penyakitnya, dan mereka mendapat azab yang pedih, karena mereka berdusta." (Q.S. Al-Baqarah [2]: $10)^{32}$

Sedangkan American Psychiatric Association (APA) mengklasifikasikan gangguan mental dalam Diagnostic and Statistical Manual of Mental Disorders edisi kelima (DSM-5) tahun 2013 sebagai berikut:

a. Neurodevelopmental disorders.

b. Schizophrenia spectrum and other psychotic disorders.

c. Bipolar and related disorders.

d. Drepessive disorders.

e. Anxiety disorders.

$f$. Obsessive-compulsive and related disorders.

g. Trauma and stressor related disorders.

h. Dissociative disorders.

$i$. Somatic symptom and related disorders.

$j$. Feeding and eating disorders.

$k$. Elimination disorders.

l. Sleep-wake disorders.

m. Sexual dysfunctions.

n. Gender dysphoria.

o. Disruptive, impulse-control, and conduct disorders.

p. Substance related and addictive disorders.

q. Neurocognitive disorders.

\footnotetext{
${ }^{29}$ Moeljono Notosoedirdjo dan Latipun, Kesehatan Mental..., 123.

${ }^{30}$ Syamsu Yusuf, Kesehatan Mental Persepektif..., 140.

31 Moeljono Notosoedirdjo dan Latipun, Kesehatan Mental..., 35. dan (Putri, Wibhawa, \& Gutama, 2015: 255)

${ }^{32}$ Kementrian Agama RI, Al-Qur'an dan Terjemahannya, (Jakarta: PT. Tehazed, 2010), 3.
} 
r. Major or mild frontotemporal neurocognitive disorders.

s. Personality disorders.

t. Paraphilic disorders.

u. Other mental disorders.

Orang yang sehat mentalnya dapat melakukan adaptasi (penyesuaian diri) terhadap lingkungannya. dia dengan mudah menempatkan diri pada perubahan sosial dan selalu aktif berpartisipasi untuk kemajuan komunitas, masyarakat dan bangsanya. Sebaliknya, orang yang memiliki gangguan mental, hidupnya hanya akan menjadi beban bagi dirinya sendiri, orang lain dan lingkungan sekitarnya. ${ }^{33}$

\section{F. Konsep PAI Zakiah Daradjat}

Pendidikan dalam bahasa Arab di sebut tarbiyah dengan kata kerja rabba. Sedangkan pengajaran dalam bahasa Arab disebut ta'lim dengan kata kerjanya 'allama. Pendidikan dan pengajaran dalam bahasa Arabnya disebut tarbiyah wa ta'lim. Sedangkan pendidikan Islam disebut tarbiyah Islamiyah. Selain kata tarbiyah dan ta'lim menurut Zakiah kata $t a$ 'dib dari kata kerja addaba juga mengandung arti pendidikan. ${ }^{34}$

Pendidikan Islam menurut Zakiah Daradjat adalah usaha, kegiatan, cara dan alat yang dapat membimbing dan mengubah sikap serta tingkah laku yang sesuai dengan ajaran Islam demi terbentuknya kepribadian muslim. Sedangkan pendidikan agama Islam menurut Zakiah Daradjat adalah pendidikan yang berdasarkan ajaran-ajaran agama Islam, yaitu berupa bimbingan, asuhan terhadap anak didik, agar nantinya setelah selesai dari pendidikan ia dapat memahami, menghayati, dan mengamalkan ajaranajaran agama Islam sebagai pandangan hidupnya (way of life) demi keselamatan dan kesejahteraan hidup di dunia maupun di akhirat.

Menurut Zakiah Daradjat, landasan pendidikan Islam terdiri dari Al-Qur'an, Sunnah Nabi Muhammad dan ijtihad seperti al-maslahah al-mursalah, istihsan, qiyas, dan sebagainya. ${ }^{35}$

Dalam Al-Qur'an Surat An-Nisa' ayat 59 juga disebutkan bahwa perintah Allah dalam Al-Quran, perintah Rasul yang terdapat dalam Hadis dan pendapat Ulil Amri, dalam hal ini adalah tokoh/ulama yang mempunyai kapasitas keilmuan dapat dijadikan landasan atau dasar pendidikan agama Islam.

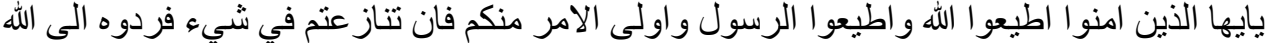

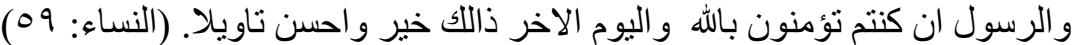

"Wahai orang-orang yang beriman! Taatilah Allah dan taatilah Rasul (Muhammad), dan Ulil Amri (pemegang kekuasaan) di antara kamu. Kemudian, jika kamu berbeda pendapat tentang sesuatu, maka kembalikanlah kepada Allah (AlQur'an) dan Rasul (sunnahnya), jika kamu beriman kepada Allah dan hari kemudian. Yang demikian itu, lebih utama (bagimu) dan lebih baik akibatnya." (Q.S. An-Nisa' [4]: 59) Kementrian Agama RI, Al-Qur'an dan Terjemahannya, (Jakarta: PT. Tehazed, 2010), h. 114.

Sejalan dengan ayat di atas, Rasullullah Saw menjelaskan dalam sabdanya bahwa Al-Qur'an dan Sunnah adalah pedoman bagi umatnya agar tidak tersesat.

$$
\text { وسنة نبيه (رواه مالكه) بلغه أن رسول الله }
$$

${ }^{33}$ William E. Narrow et al., Diagnostic and Statistical Manual of Mental Disorders, Fifth Edition, (Washington DC: American Psychiatric Publishing, 2013), 42.

${ }^{34}$ Zakiah Daradjat, Ilmu Pendidikan Islam, (Jakarta: PT Bumi Aksara, 2016), Cet. XII, 25-26.

${ }^{35}$ Zakiah Daradjat, Ilmu Pendidikan Islam, (Jakarta: PT Bumi Aksara, 2016), Cet. XII, 19. 
"Dari Malik bin Anas bahwasanya Rasulullah Saw bersabda: Aku tinggalkan kepada kalian dua perkara yang kalian tidak akan tersesat selama berpegang teguh pada keduanya, yaitu Kitab Allah (al-Quran) dan Sunnah Nabi.” (HR. Malik).

Dapat disimpulkan bahwa landasan atau dasar pendidikan agama Islam secara prinsip diletakkan pada dasar-dasar ajaran Islam dan seluruh perangkat kebudayaannya. Dasar-dasar pembentukan dan pengembangan pendidikan agama Islam yang utama adalah Al-Qur'an, Hadis, Ijma dan Qiyas di samping pengembangan atas dasar utama tersebut melalui pemahaman para ulama berupa ijtihad di antaranya, Qiyas, Istishab, Istihsan, Urf, dan Maslahah Mursalah, Syar'u Man Qablana, Mazhab Shahabi dan Saddu al-Dzari'ah.

Zakiah Daradjat menambahkan pendidikan agama Islam mempunyai tujuantujuan yang berintikan pada tiga aspek, yaitu iman, ilmu dan amal. Pada dasarnya, ketiganya berisi: a) mengembangkan serta membentuk sikap positif dan disiplin, serta cinta terhadap agama dalam pelbagai kehidupan anak yang nantinya diharapkan menjadi manusia yang bertakwa kepada Allah Swt. dan taat kepada perintah Allah dan RasulNya. b) ketaatan kepada Allah Swt. dan Rasul-Nya merupakan motivasi intrinsik terhadap pengembangan ilmu pengetahuan yang dimiliki oleh anak. Pemahaman tentang pentingnya agama dan ilmu pengetahuan, anak akan menyadari keharusan menjadi hamba Allah yang beriman dan berilmu pengetahuan. c) menumbuhkan dan membina keterampilan beragama dalam semua lapangan kehidupan serta dapat memahami dan menghayati ajaran agama Islam secara mendalam dan menyeluruh, sehingga dapat digunakan sebagai pedoman hidup, baik dalam hubungan dirinya dengan Allah melalui ibadah, hubungan dengan sesama manusia yang tercermin dalam akhlak perbuatan, dan hubungan dengan alam sekitar melalui pemeliharaan, pengolahan dan pemanfaatannya. $^{37}$

Pendidikan agama Islam dilihat dari segi makna maupun tujuannya haruslah mengacu pada penanaman nilai-nilai Islam dan juga etika sosial maupun moralitas sosial. Penanaman nilai-nilai ini dalam rangka meraih keberhasilan hidup (hasanah) di dunia, yang kemudian akan menuai kebaikan (hasanah) di akhirat kelak bagi peserta didik. $^{38}$

Demikianlah prinsip pokok ajaran Islam yang harus menjadi prinsip dalam merumuskan tujuan pendidikan agam Islam. Menurut Zakiah tujuan pendidikan agama Islam harus berisi sesuatu yang menumbuhkan, menyuburkan, dan mengembangkan keyakinan beragama, mengamalkan ajarannya, memelihara dan menyalurkan pertumbuhan dan perkembangan rohani serta jasmani, membina dan menjaga kesejahteraan jiwa dan raga menurut norma-norma yang digariskan oleh ajaran Islam.

\section{G. Integrasi Kesehatan Mental Dengan Good Governance}

Kesehatan mental adalah terhindarnya seseorang dari gangguan dan penyakit kejiwaan, mampu menyesuaikan diri, sanggup menghadapi masalah-masalah dan kegoncangan-kegoncangan biasa, adanya keserasian fungsi-fungsi jiwa dan merasa bahwa dirinya berharga dan berguna serta dapat menggunakan potensi yang ada pada dirinya dengan menggunakan pola pikir. ${ }^{39}$ Pola pikir adalah pola-pola dominan yang menjadi acuan utama seseorang untuk bertindak. Selanjutnya dikatakan bahwa pola

\footnotetext{
${ }^{36}$ Imam Malik bin Anas, Al-Muwatha', (Kairo: Daar al-Hadis, 2005), 622.

${ }^{37}$ Zakiah Daradjat, Ilmu Pendidikan Islam ..., 89-90

${ }^{38}$ Abdul Majid Abdul Majid, Belajar dan Pembelajaran..., 18.

${ }^{39}$ Zakiah Daradjat, Islam dan Kesehatan Mental..., 9.
} 
pikir adalah pola yang menetap dalam pikiran bawah sadar seseorang. ${ }^{40}$ Mindset sangat besar pengaruhnya dalam pengembangan budaya kerja. Hal tersebut disebabkan karena pengembangan budaya kerja membutuhkan fleksibilitas berpikir khususnya apabila pengembangan budaya kerja berlawanan dengan apa yang dianut sebelumnya. Begitu pentingnya Mindset sehingga Inbavanan menyatakan bahwa yang memprihatinkan pada masa turbulensi seperti sekarang adalah sikap dan perilaku yang masih menggunakan pola-pola pikir yang lama. ${ }^{41}$

Pemerintah adalah suatu organisasi yang memiliki kekuasaan untuk membuat dan menerapkan hukum serta undang-undang di suatu wilayah tertentu. Setelah runtuhnya kekuasaan pemerintahan orde baru maka akan membawa perubahan dalam pemerintahan. Pemerintah yang baik adalah pemerintah yang mampu menyelenggarakan pemerintahan, melaksanakan pembangunan, menyelenggaarakan pelayanan publik, dapat mengelola anggaran negara dengan baik, tepat sasaran dan dimanfaakan untuk mensejahterakan rakyat serta demokratis. Alhasil, aparatur pemerintah merupakan pengatur sekaligus pelayan masyarakat yang memberikan pelayanan yang jujur, adil, profesional dan merata, bekerja secara efisien dan efektif dalam mengemban tugas negara untuk mencapai tujuan negara juga ikut dalam proses pertanggung jawaban terhadap kesejahteraan masyarakat sebagai pihak yang dilayani. Maka dari itu, aparatur yang telah memiki pemahaman yang komprehensif maka akan memegang teguh prinsip-prinsip Good Governance sehingga akan terwujudnya pemerintahan yang baik dan bersih dan mampu bekerja dalam tim. ${ }^{42}$

Birokrasi merupkan organisasi pemerintah yang terdiri dari beberapa bagian struktur yang memiliki hubungan satu dengan yang lain dan memiliki fungsi, peran, tujuan dan kewenangan dalam melaksanakan program pemerintahan untuk mencpai visi, misi, tujuan dan program yang telah dirancang. Peran dan fungsi birokrasi meliputi hal berikut: 1. Melaksanakan pelayanan publik, 2. Melakukan pembangunan yang profesional, 3. Perencanaan, pelaksanaan dan pengawasan kebijakan, 4. Alat pemerintah untuk melayani masyarakat dan negara.

Secara sederhana pengertian reformasi birokrasi, pelayanan publik, dan pemberantasan korupsi bermakna sebagai berikut : Reformasi Birokrasi adalah (1) perubahan mindset, cara berpikir (pola pikir, pola sikap, dan pola tindak); (2) perubahan penguasa jadi pelayan; (3) mendahulukan peran dari wewenang; (3) tidak berpikir output, tetapi outcome; (4) perubahan manajemen kinerja; dan (5) pemantauan percontohan keberhasilan (best practices); dalam mewujudkan good governance, clean government (pemerintah bersih), transparan, akuntabel, dan profesional), dan bebas KKN. Pelayanan publik, ditandai tiga hal, yaitu apa syaratnya, berapa biayanya, dan kapan selesainya pelayanan? Pemberantasan korupsi, mulailah dari diri sendiri, keluarga, dan lingkungan kerja, serta upayakan membangun akhlak mulia/akhlakul karimah (kejujuran/siddiq, keteladanan/tabligh, terpercaya/amanah, profesional dan kreatif/fathonah, dan konsisten/istiqomah). Korupsi terjadi karena ada Niat dan Kesempatan, karena itu harus dihilangkan Niat dan Kesempatan melakukan tindak pidana korupsi. $^{43}$

\footnotetext{
40 (Agus Maryono, Pola Pikir Sistem, Yogyakarta: Gadjah Mada University Press, 2015: XXI)

${ }^{41}$ Inbavanan, G. (2018). People Focus in a VUCA World. NHRD Network Journal, 11(3), 22.)

42 Dr. H. Tobari, S.E., M.Si., Membangun Budaya Organisasi pada Instansi Pemerintahan, Yogyakarta: deepublish, 2015, 1.

${ }^{43}$ Lombongbitung, C., Mantiri, M., \& Waworundeng, W. (2018). REFORMASI BIROKRASI DI DINAS KELAUTAN DAN PERIKANAN KOTA BITUNG. JURNAL EKSEKUTIF, 1(1) : 2.
} 
Salah satu kelemahan yang ada dikalangan PNS selama ini adalah terlalu terikat dengan urusan tugas sehingga rasa kebersamaan kurang. Akibat dari terlalu terikat dengan uraian tugas dimaksud banyak diantara mereka yang berpikir untuk bagiannya saja tanpa memikirkan visi dan misi organisasi secara keseluruhan. Sebagai contoh sering kita dengar ungkapan yang menyatakan: "Itu bukan tanggung jawab bagian kami" atau "itu bukan urusan kami" dan sebagainya. Padahal yang ditanyakan tersebut adalah urusan instansi yang bersangkutan.

Pandangan berpikir yang demikian tentunya perlu segera diubah sehingga ada perubahan paradigma berpikir dari berpikir bagian ke berpikir menyeluruh. Hal ini sesuai dengan pandang sistem yang bersifat menyeluruh, yang memberikan makna berbeda dari hanya sekedar menjumlahkan bagian-bagian sistem. Paradigma berpikir bagian atau berpikir terkotak-kotak dimaksud tidak sejalan dengan semangat reformasi birokrasi yang sekarang dikembangkan. Oleh karena itu paradigma yang demikian hendaknya diubah artinya PNS harus mampu berpikir menyeluruh, bukan berpikir terkotak-kotak dan mementingkan ego kelompok.

"Berpikir" mencakup banyak aktivitas mental. Misalnya berpikir saat memutuskan mengerjakan pekerjaan tertentu, berpikir tentang membeli barang tertentu, berpikir tentang karyawan mana yang perlu dipromosikan dan sebagainya. Maka penting peran mental yang sehat dalam sebuah individu personal di ruang lingkup pemerintahan. Agar tercipta kinerja yang masif, terstruktur, dan bersih dari korupsi dan nepotisme demi sejahteranya rakyat. ${ }^{44}$

Prinsip bekerja mencari uang, jabatan, pangkat dan kedudukan dirubah memiliki prinsip bekerja karena ibadah. Dengan berprinsip seperti ini kita akan mendapatkan segalanya. Rejeki tidak akan pernah tertukar, karena sang pencipta telah menentukan takdir setiap hamba-Nya. Dengan menerapkan prinsip ini, maka seorang PNS akan memiliki dua dimensi nilai dalam pelaksanaan tugasnya. Dimensi pertama adalah dimensi Uluhiah yaitu dimensi ke-Tuhan-an dimana dia akan memperoleh imbalan pahala sebgai ibadah disisi Allah. Sebagai konsekuensi dimensi ini adalah dia harus bekerja dengan segenap kemampuan terbaiknya, karena Allah itu Indah dan Maha Baik dan Ia hanya menerima sesuatu yang Indah dan baik saja. Dimensi kedua adalah dimensi keduniaan dimana dia akan mendapatkan prestasi yang baik dalam pelaksanaan tugasnya dan sekaligus akan mendapatkan penilaian yang baik pula dari atasannya. Seorang PNS perlu menyadari bahwa tugas yang dipercayakan kepadanya tidak hanya akan dipertanggungjawabkannya secara dinas, tetapi juga di depan Allah. Pertanggungjawaban secara kedinasan bisa luput dari jangkauan karena sesuatu atau banyak sebab, tetapi pertanggungjawaban di depan Allah nanti di akhirat tidak akan mungkin dihindarkan. Oleh karena itu PNS perlu: (1) benar-benar taat menjalankan perintah agama, yaitu mengerjakan segala yang diperintahkan agama dan menjauhi segala yang dilarang agama; (2) benar-benar taat menjalankan perintah kedinasan, yaitu mengerjakan segala yang diperintahkan dalam tugas, seperti bekerja jujur, giat, disiplin, dedikatif, dan menjauhi segala yang dilarang dalam tugas. ${ }^{45}$

44 Hernawaty, T., Setyorini, D., Maulana, I., \& Arifin, H. S. (2018). Pembentukan Kader Kesehatan Jiwa Di Kabupaten Pangandaran. Jurnal Pengabdian Kepada Masyarakat, 2(9): 818).

${ }^{45}$ Zakiah Daradjat, Peranan Agama dalam Kesehatan Mental, (Jakarta: Gunung Agung, 2001), Cet. XVI, 83. 


\section{H. Kesimpulan}

Kondisi mental memang sangat menentukan dalam hidup ini. Hanya orang yang sehat mentalnya yang dapat merasa bahagia, mampu, berguna, dan sanggup menghadapi segala permasalahan dalam hidup. Apabila kesehatan mental terganggu akan tampak gejalanya dalam segala aspek kehidupan, perasaan, pikiran, perilaku dan kesehatan.

Agama adalah faktor penting dalam pembinaan mental seseorang, baik pembinaan sejak dari kecil ataupun pembinaan setelah dia dewasa. Agama menjadi unsur penting yang sangat menentukan dalam konstruksi kepribadian seseorang sejak kecil. Apabila seseorang yang tumbuh menjadi remaja atau dewasa tanpa mengenal agama, maka dia akan berperilaku kurang baik saat terjadi gangguan jiwa.

Karena nilai-nilai positif yang tetap dan tidak akan berubah adalah nilai-nilai agama. Sedangkan nilai-nilai sosial dan moral yang didasarkan bukan pada agama, akan sering mengalami perubahan, sesuai perkembangan zaman dan perkembangan masyarakat itu sendiri. Oleh sebab itu, mental yang terbina hanya dari nilai-nilai sosial dan moral yang mungkin berubah akan membawa pada goncangan jiwa apabila perubahan itu terjadi.

Agama merupakan unsur penting dalam pembinaan mental. Tanpa agama, rencana-rencana pembangunan tidak akan terlaksana dengan sebaik-baiknya. Karena seseorang dapat melaksanakan rencananya dengan baik bergantung pada ketenangan jiwanya. Jika jiwanya gelisah dia tidak akan sanggup menghadapi masalah yang terdapat dalam pelaksanaan rencana-rencana tersebut. Mental yang tumbuh tanpa agama belum tentu akan dapat mencapai integritas dikarenakan kurangnya ketenangan dan ketentraman jiwa.

Kesehatan mental adalah terwujudnya ketentraman jiwa, oleh karenanya agama memberikan berbagai pedoman dan petunjuk agar ketentraman jiwa dapat tercapai. Hal ini sesuai dengan Q.S. Al-Fath ayat 4:

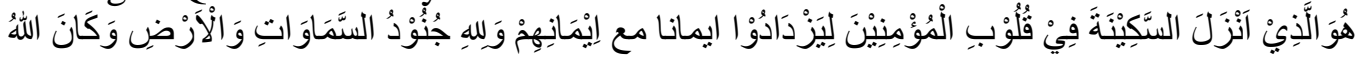

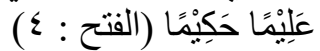

"Dialah yang telah menurunkan ketenangan ke dalam hati orang-orang mukmin untuk menambah keimanan atas keimanan mereka (yang telah ada). Dan milik Allahlah tentara langit dan bumi dan adalah Allah Maha mengetahui lagi Maha Bijaksana." (Q.S. Al-Fath [48]: 4)

Agama memberikan penyelesaian terhadap permasalahan, pedoman juga bimbingan disegala bidang sendi kehidupan, baik untuk orang kecil, buruh, pekerja kasar, maupun bagi orang-orang besar seperti, pemimpin, majikan, dan sebagainya. Bahkan juga bagi kehidupan berkeluarga, bertetangga, bermasyarakat, dan sebagai pengendali moral bagi setiap pribadi, sehingga terwujud kehidupan yang bahagia, bergairah dan penuh semangat.

Pendidikan Agama Islam adalah pendidikan yang berdasarkan ajaran-ajaran agama Islam, yaitu berupa bimbingan, asuhan terhadap anak didik, agar nantinya setelah selesai dari pendidikan ia dapat memahami, menghayati, dan mengamalkan ajaranajaran agama Islam sebagai pandangan hidupnya (way of life) demi keselamatan dan kesejahteraan hidup di dunia maupun di akhirat.

Menurut Zakiah Daradjat, landasan pendidikan Islam terdiri dari Al-Qur'an, Sunnah Nabi Muhammad dan ijtihad seperti al-maslahah al-mursalah, istihsan, qiyas, dan sebagainya. 
Secara garis besar Zakiah Daradjat mengemukakan tujuan pendidikan Islam adalah untuk membina manusia agar menjadi hamba Allah yang saleh dengan seluruh aspek kehidupannya, perbuatan, pikiran, dan perasaannya. Tujuan pendidikan Islam ialah membentuk kepribadian muslim, yaitu suatu kepribadian yang seluruh aspeknya dijiwai oleh ajaran Islam. Orang yang berkepribadian muslim dalam Al-Qur'an disebut muttaqin. Karena itu pendidikan Islam bertujuan juga membentuk manusia yang bertakwa.

\section{DAFTAR PUSTAKA}

Hasanah, M. (2017). Pengaruh Gadget terhadap Kesehatan Mental Anak. Indonesian Journal of Islamic Early Childhood Education.

Idi, A., \& Sahrodi, J. (2017). Moralitas Sosial dan Peranan Pendidikan Agama. Intizar. https://doi.org/10.19109/intizar.v23i1.1316

Kemendikbud RI, B. P. dan P. B. (2016). Hasil Pencarian - KBBI Daring. Badan Pengembangan Dan Pembinaan Bahasa, Kementerian Pendidikan Dan Kebudayaan Republik Indonesia.

Putri, A. W., Wibhawa, B., \& Gutama, A. S. (2015). KESEHATAN MENTAL MASYARAKAT INDONESIA (PENGETAHUAN, DAN KETERBUKAAN MASYARAKAT TERHADAP GANGGUAN KESEHATAN MENTAL). Prosiding Penelitian Dan Pengabdian Kepada Masyarakat. https://doi.org/10.24198/jppm.v2i2.13535

Republik Indonesia. Undang-Undang Republik Indonesia Nomor 18 Tahun 2014. , Sekretariat Negara Republik Indonesia § (2014).

Widayatun, \& Fatoni, Z. (2013). Kesehatan Mental dalam Kedaruratan. Jurnal Kependudukan Indonesia.

Wijayanti, A. (2016). Strategi Coping Dan Subjective Well Being Remaja Pasca Aborsi Di Samarinda. Psikoborneo. 